\title{
Economic and legal factors of investment in subsoil use in the aspect of implementation sustainable development concepts
}

\author{
Gennady Alexandrov, and Alexander Yablonev * \\ Tver State Technical University, 170026, Af. Nikitin emb., 22, Tver, Russia
}

\begin{abstract}
Following the paradigm of sustainable development presupposes a balanced solution of three tasks: ensuring economic growth, achieving social progress and improving the quality of the environment. However, the solution of environmental and social problems causes restrictions on economic activities. In this regard, there is a need to develop methodological approaches to the formation of organizational and economic relations and mechanisms in order, firstly, to resolve the contradictions between the economic and socio-environmental, and, secondly, to provide motivation to activate investment processes in a direction conducive to achieving goals of sustainable development of subsoil use. The problem of investment attractiveness becomes even more urgent, taking into account the special nature of industrial relations developing in subsoil use, which must be taken into account when implementing the concept of sustainable development.
\end{abstract}

\section{Introduction}

This study aims to consider a number of issues, the relevance of which is due to the implementation in the Russian Federation of the concept of transition to sustainable development in accordance with the decisions of the World Commission on Environment and Development (WCED). They consider sustainable development as a harmonious, balanced development of economic, social and environmental processes. This means that natural resource development, investment, scientific and technological advances, personal development and institutional change must be aligned and strengthen current and future capacities to meet human needs and aspirations. At the same time, in the scientific community, attention is drawn to the difficulties of its practical implementation, since the problem of combining economic growth with environmental and social goals arises $[1,2]$. At present, there are also critical considerations regarding the very principles of sustainable development [3]. It is pointed out, in particular, that universal for different countries declarations of the priority of human rights and interests acquire in the conditions of globalization peculiar forms of international domination of economically developed countries, reminiscent of the colonial era [4]. Nevertheless, the UN Conference on Environment and Development (Rio de Janeiro, 1992) adopted a program document on the

*Corresponding author: alvovich@mail.ru 
implementation of the concept of sustainable development - A Program of Action for Sustainable Development and Rio Declaration. Later, in the Russian Federation, as well as in other countries, the Concept of Transition to Sustainable Development was adopted and approved in 1996 (Presidential Decree No. 440 of 01.04.1996). And since subsoil use is a special type of activity, then when implementing the concept of sustainable development in this area, along with general approaches, its features should be taken into account. The latter are reflected, among other things, on the investment activities of mining enterprises.

\section{Main}

The implementation of the concept of sustainable development cannot do without the mobilization of investment funds, which are necessary for the implementation of economic, as well as social and environmental practices. However, as noted above, in general, at the macro level, ensuring their balance is quite difficult. But, naturally, the origin of these difficulties and problems should be sought, first of all, at the micro level, that is, at the level of primary production links - enterprises.

It is in the process of production activities that contradictions arise that affect the interests of business. And, by definition, the most important of them is the contradiction between, on the one hand, the achievement of the intended financial and economic results, and on the other, the presence of environmental and social restrictions on economic and, above all, investment activities. In turn, as stated in a number of modern publications, this generates social fears, which become an integral part of human existence [5] and make it necessary to take into account such non-traditional factors as components of social fears when solving issues of motivating investors [6]. Removing such contradictions is adequate to solving the problem of transforming enterprises into objects that are attractive for investment, capable of balancing the tasks of ensuring economic growth, achieving social progress and improving the quality of the environment. However, for its implementation, it is important to create conditions for enterprises to ensure that they attract sustainable investments. For this, it is necessary, firstly, to identify and remove barriers and restrictions, threats and challenges that negatively affect the investment attractiveness of enterprises and, secondly, to develop adequate institutional measures of a motivational and stimulating nature, that ensure the resolution of these contradictions.

Since the object of our research is subsoil use, the solution to this problem is based on the understanding, that very specific production relations are developing in its industries (for details, see: [7]). They are due to the presence of two types of property relations: firstly, regarding the ownership and disposal of subsoil and, secondly, regarding their use (by an entrepreneur) as an object of management. Therefore, between the owner of the subsoil and the economic entity, special (rent) relations arise, in which a contradiction is inherently inherent in the interests of appropriating income from economic activities. However, since the Russian State is not only the owner of the subsoil and the subject of rent relations, but at the same time the recipient of rent and the conductor of the concept of sustainable development, it is quite capable of resolving these contradictions through the institutionalization of organizational and economic relations and clothe them in an adequate legal framework. It is in its power to ensure the resolution of the contradictions between the economic interests of entrepreneurs and the State, arising from the fact, that imputing to business the implementation of the goals of social and environmental development limits its opportunities to obtain higher financial results. Specifically, we are talking about creating mechanisms for regulating rent relations and administering taxes, the use of which should positively affect the investment attractiveness of subsoil use objects [7,8].

Attention should be paid to the fact that the above only to a small extent reveals the specifics of economic relations in subsoil use, and therefore those factors, that form the idea 
of the investment attractiveness of enterprises of extractive activities. At the same time, this phenomenon itself can be understood by analyzing the totality of social, economic, organizational, legal factors, as well, as political and socio-cultural conditions that predetermine the motivation and incentives to invest in subsoil use. At the same time, subsoil use occupies a certain place in the national economy, and is represented in a number of regions. It is at their level that the legal framework is formed in which subsoil use is carried out. In addition, the situation with attracting investments in this type of activity is determined by what specific factors, what is their origin, and how they manifest themselves at the regional and federal levels of the economic hierarchy, while influencing the investment attractiveness of enterprises [9]. Naturally, in terms of the implementation of sustainable development goals and their achievement by attracting investments, in the first place it is necessary to identify the most important factors in the aggregate of economic, administrative-legal and socio-environmental factors, and assess their impact on the investment attractiveness of specific subsoil use objects. It should be borne in mind, that the latter can be factors, on the one hand, limiting the implementation of investment activities, but, on the other hand, introduced as restrictions for solving problems of an environmental and social nature.

\section{Conclusion}

The considered situation with the implementation of the concept of sustainable development in subsoil use indicates the need for a more in-depth theoretical study of the problems of economic relations emerging in the field of subsoil use. At the same time, as shown in this article, the development of specific, effective measures and, in general, an economic mechanism, that ensure the resolution of objectively existing contradictions between economic entities, depends on their solution. First of all, this concerns solving the problem of coordinating and realizing the interests of the subjects of extractive activities, that is, the owners of mineral deposits and economic entities (entrepreneurs). As a result, this will help to increase the motivation and interest of the latter in making sustainable investments, and, accordingly, in the implementation of the concept of sustainable development of the subsoil use sphere.

The reported study was funded by RFBR, project number 20-010-00124.

\section{References}

1. R. Costanza, C. Folke, Ecological Economics and Sustainable Development. Paper prepared for the international Experts Meeting for the Operationalization of the Economics of Sustainability (Manila, Philippines, 1994)

2. J. Clapp, Advances in International Environmental Politics, 107-136 (2014)

3. G. Melina, S. Yang, L. F. Zanna, Econ. Mod. J. 52, 630-649 (2016)

4. D. Chandler, Int. J. of Security and Dev., 4 (1), 1-14 (2005)

5. B. Grace Li, P. Gupta, J. Yu. Int. Econ., 151, 7-25 (2017)

6. A. Berg, R. Portillo, S.-C. S. Yang, L.-F. Zanna, IMF Econ. Rev., 61(1), 92-129 (2013)

7. G. Alexandrov, A. Iablonev, E3S Web of Conf., 41, 0424 (2018)

8. G. Alexandrov, A. Yablonev, E3S Web of Conf., 105, 0421 (2019)

9. Ch. P. Jones, Investments: Analysis and Management (John Wiley \& Sons Inc., New York, 2012) 